\title{
La visión de los gobiernos brasileros sobre China (2003-2020) por medio de la teoría del rol*
}

\author{
Angelo Flórez de ANDRAdE** \\ Carlos Alberto Chaves García***
}

Artículo recibido: 12 de mayo de 2020

Artículo aprobado: 8 de febrero de 2021

Doi: https://doi.org/10.12804/revistas.urosario.edu.co/desafios/a.9031

Para citar este artículo: Flórez de Andrade, A., \& Chaves García, C. A. (2021). La visión de los gobiernos brasileros sobre China (2003-2020) por medio de la teoría del rol. Desafíos, 33(1), 1-40. https://doi.org/10.12804/revistas.urosario.edu.co/desafios/a.9031

\section{Resumen}

China es en la actualidad el principal socio comercial de Brasil. Sus relaciones van más allá de lo comercial y se extienden a cooperación en temas educativos, tecnológicos, políticos. En este artículo se presenta el análisis de la percepción de diferentes gobiernos brasileros sobre los gobiernos de la República Popular de China (RPC) de 2003 a 2019, utilizando la teoría de rol de Kalevi Holsti. Para la realización de este trabajo se hizo un análisis cualitativo de contenido de fuentes primarias a partir de la revisión de documentos oficiales como planes de desarrollo y discursos de los

\footnotetext{
* Este artículo es resultado de los avances del proyecto de investigación "Análisis de las relaciones diplomáticas Colombia China: obstáculos, potencialidades y desafíos para una asociación estratégica". Código 2036501, avalado y financiado por la Universidad Santo Tomás, Bogotá.

** Universidad Santo Tomás. Bogotá, Colombia. Correo electrónico: angeloflorez@usantotomas.edu.co ORCID: http://orcid.org/0000-0003-0411-9271

*** Universidad Santo Tomás. Bogotá, Colombia. Correo electrónico: carloschaves@usantotomas.edu.co ORCID: http://orcid.org/0000-0002-5324-3431
} 
diferentes gobiernos brasileros. Al revisar estos documentos se encontraron marcadas diferencias entre los roles asignados a China por los gobiernos del Partido de los Trabajadores, el gobierno Temer y el gobierno Bolsonaro.

Palabras clave: politica exterior; politica exterior brasilera; Brasil; China; roles nacionales.

\title{
How Brazilian Governments (2003-2019) view China: A Role Theory Analysis
}

\begin{abstract}
China is Brazil's most important trading partner. Relations between China and Brazil go beyond trading issues and extend to cooperation on educational, technological, and political issues. This article analyzes the perception of the Brazilian governments (2003-2019) about the Chinese government, using Kalevi Holsti's role theory. We undertook qualitative content analysis of official documents, such as development plans and discourses of the different Brazilian governments. After analyzing the material, marked differences were found between the roles assigned to China by the governments of the Workers' Party, the Temer government, and the Bolsonaro government.
\end{abstract}

Keywords: Foreign policy; brazilian foreign policy; Brazil; China; national roles.

\section{A visão dos governos brasileiros sobre a China (2003-2020) por meio da Teoria do Rol}

\begin{abstract}
Resumo
A China é atualmente o principal parceiro comercial do Brasil. As relacões entre China e o Brasil vão além do campo comercial e se estendem à cooperação em questões educacionais, tecnológicas e politicas. Neste artigo analisou-se a percepção dos diferentes governos brasileiros sobre os governos da República Popular da China no período de 2003 a 2019 usando a Teoria do Rol, de Kalevi Holsti. Para a realização deste trabalho, utilizou-se uma análise qualitativa do conteúdo das fontes primárias a partir da revisão de documentos oficiais como Planos de Desenvolvimento e discursos
\end{abstract}


dos diferentes governos brasileiros. Com a revisão desses documentos, encontraram-se diferenças marcantes entre os papéis atribuídos à China pelos governos do Partido dos Trabalhadores, pelo governo Temer e pelo governo Bolsonaro.

Palavras-chave: politica externa; politica externa brasileira; Brasil; China; papéis nacionais.

\section{Introducción}

Una vez finalizada la Guerra Civil China (1927-1949), la República de China, que incluía la isla de Taiwán, y la República Popular de China (RPC), que controlaba la gran mayoría del territorio chino, se disputaron internacionalmente el reconocimiento del gobierno legítimo del país. Dada la Guerra Fría, Estados Unidos y sus aliados, incluido Brasil, reconocieron al gobierno de Taiwán como China sobre la RPC (Esteban, 2005).

En 1974, Brasil modificó su reconocimiento inicial del gobierno de Taiwán como el gobierno oficial de China y estableció relaciones diplomáticas con la RPC. En buena parte, el reconocimiento de Brasil a la RPC se explica por la admisión de esta en la Organización de Naciones Unidas (ONU) en 1971 y al acercamiento diplomático entre Estados Unidos y la RPC durante esa misma década (Brasil de Holanda, 2016).

En la actualidad, China y Brasil demuestran una sólida relación. En el plano comercial, la relación entre ambos Estados es bastante fructífera. Desde 2009, China se ha convertido en el principal destino de las exportaciones del gigante suramericano (Serra, 2016). Las relaciones entre ambos países no están exclusivamente marcadas por el buen desempeño del comercio, prueba de ello es la complejidad de temas tratados en la Comisión Sino-Brasileña de Alto Nivel de Concertación y Cooperación —COSBAN- (Ministério das Relações Exteriores, 2019).

Las relaciones sino-brasileras se han mantenido durante más de 40 años a pesar de los cambios ideológicos extremos que ha vivido Brasil. Ante estos cambios, vale la pena preguntarse cuál es la visión 
que han tenido los diversos gobiernos brasileros de sus pares de la RPC. El marco temporal de esta investigación va desde 2003 hasta 2019. Por lo tanto, se analizará la forma en la cual los gobiernos de Luiz Inácio “Lula” da Silva (2003-2010), Dilma Roussef (2011-2016), Michel Temer (2016-2018) y Jair Bolsonaro (2019-actualidad) han percibido al gobierno de la RPC.

Si bien se consideró incluir en el análisis un periodo de tiempo más extenso, la inclusión de ocho años más de análisis de material dificultaría la realización de un análisis comparativo profundo, teniendo en cuenta las limitaciones espaciales de este trabajo. Por otra parte, la inclusión en el análisis del periodo de gobierno de Fernando Henrique Cardoso restaría profundidad a la comparación entre dos gobiernos ideológicamente antagónicos como los del Partido de los Trabajadores (РT) frente al gobierno Bolsonaro (hoy en día, sin partido).

Este trabajo está dividido en cinco partes. En primer lugar, se realiza un breve repaso histórico de las relaciones bilaterales. Durante la segunda parte, se explica el marco teórico seleccionado; acto seguido, se describe la metodología diseñada. En cuarto lugar, se presentan los resultados de la investigación. Finalmente, se exponen las conclusiones.

\section{Breve historia de la relación bilateral}

El establecimiento de lazos de confianza entre Brasil y la RPC tomó tiempo, teniendo en cuenta las profundas divergencias políticas que enfrentaban ambos gobiernos durante la apertura de relaciones en 1974. Con la democratización de Brasil, la apertura china hacia el mundo y el fin del orden bipolar, ambos Estados realizarían nuevos acercamientos.

En 1988, el presidente José Sarney visitó China; producto de estos acontecimientos se creó el Programa de Satélites de Recursos Terrestres China-Brasil —China-Brazil Earth Resources Satellite (CBERS) - (Brasil de Holanda, 2016). Este instrumento de cooperación 
tecnológica ha permitido que ambos países lancen de manera conjunta al menos cuatro satélites de observación terrestre (Serra, 2016).

Durante los primeros años de la década de los noventa, los presidentes Yang Shangkun y Jiang Zemin visitaron Brasil. Desde estas visitas, el gobierno chino definió su relación con Brasil como una "sociedad estratégica" (Brasil de Holanda, 2016). Bajo el gobierno de Fernando Henrique Cardoso, China se convirtió en el mayor socio comercial de Brasil en Asia (Ministério das Relações Exteriores, 2019). Para ese entonces, ambos países ya acumulaban un comercio de 1.5 billones de dólares (Cardoso, 2016).

Con la victoria electoral en Brasil de Luiz Inácio "Lula" da Silva en 2002, la relación bilateral se hizo más cercana (Nogueira Galinari, 2019). Durante los dos gobiernos de "Lula" (2003-2006; 2007-2010), Brasil y China estrecharon sus relaciones en materia comercial, política y tecnológica. La voluntad del gobierno "Lula" de cooperar con China permitió que en 2004 ambos gobiernos crearan la COSBAN (Brasil de Holanda, 2016).

En 2009, China se convirtió en el primer socio comercial de Brasil (Ministério das Relações Exteriores, 2019). Durante 2010, los presidentes Hu Jintao y "Lula" da Silva convinieron en crear el Plan de Acción Conjunta (PAC). La idea fue crear planes de acción con la finalidad de monitorear la relación bilateral, así como profundizarla en materia energética, científica, tecnológica, cultural y educativa (da Silva \& Jintao, 2016).

En 2010, Brasil enfrentó unas elecciones en las cuales Dilma Rousseff, candidata del PT y cercana aliada de "Lula" fue elegida. La presidente Rousseff se comprometió a continuar con el camino trazado por "Lula" frente a China (Ministério das Relações Exteriores, 2011). Bajo su mandato, se mantendrían en funcionamiento el COSBAN, el CBERS y el PAC 2012-2021 e incluso se construiría un nuevo PAC (Ministério das Relações Exteriores, 2019). 
El gobierno de Rousseff promovería la articulación de acciones entre Brasil y China no solo en la ONU, la Organización Mundial del Comercio (OMC) y el BRICs (Brasil, Rusia, India, China y Suráfrica), ${ }^{1}$ sino también ante el Fondo Monetario Internacional (FMI), el Banco Mundial y organizaciones plurilaterales como el G20, el grupo BASIC (Brasil, Suráfrica, India y China, por sus siglas en portugués) y el G77+China. Dada la importante integración entre ambos gobiernos, en 2012 el gobierno chino elevó su relación con Brasil a la categoría de "sociedad estratégica global" (Serra, 2016).

En 2016, Dilma Rousseff fue destituida de su cargo por el Congreso brasilero, lo que dio lugar a un cambio político que llevaría a la presidencia de Brasil al vicepresidente Michel Temer del Movimiento Democrático Brasileño (Almagro Castro, 2018). A pesar de las buenas relaciones que el gobierno Temer tuvo con China, ambos países dejaron de converger en instancias y foros multilaterales (Frenkel \& Azzi, 2019).

La orientación ideológica del gobierno Temer, más cercana a la tradición americanista de la política exterior brasilera (Costa \& Soares, 2020), buscó distanciarse y diferenciarse de los gobiernos liderados por el PT, acercó a Brasil a los intereses de Estados Unidos (EE. UU.) en instancias multilaterales como la OMC. Durante la presidencia de Temer, el gobierno buscó el ingreso de Brasil al Acuerdo Transpacífico de Cooperación Económica (TPP) y al Acuerdo General sobre el Comercio de Servicios —AGCS- (Frenkel \& Azzi, 2019).

En 2018 se realizaron nuevas elecciones presidenciales en Brasil; en ese entonces uno de los candidatos con más opciones de ganar la presidencia era el derechista Jair Bolsonaro del Partido Social-Liberal (PSL). Durante la campaña electoral, el político nacionalista brasilero llegó a afirmar que China era un país "predador" (Malamud, 2018).

Como candidato presidencial, Bolsonaro visitó Taiwán en marzo de 2018; fue el primer candidato presidencial que visitaba la isla desde el

1 Corresponde al grupo de economías emergentes. 
establecimiento de relaciones entre Brasil y China, hecho que demostraría la hostilidad del candidato hacia la RPC (Lapper, 2019). A pesar de la retórica electoral de Bolsonaro y sus prioridades ideológicas, su gobierno ha mostrado interés por mantener relaciones con China, particularmente en el terreno económico, dados los fuertes vínculos en términos de comercio, inversiones y recursos financieros.

\section{Marco teórico}

Una vez hecha una contextualización de las relaciones sino-brasileras, es necesario regresar al tema central de esta investigación: el análisis sistemático de la visión de los gobiernos brasileros entre 2003 y 2019 hacia el gobierno de la RPC. Con este propósito resultó fundamental seleccionar una teoría que brindara la posibilidad de cumplir con el objetivo central de investigación. Para ello, los autores justifican en qué campo disciplinar se encuentra la investigación. Posteriormente, se evalúan las opciones teóricas que mejor permiten cumplir con el objetivo central de la investigación. Finalmente, exponen elementos fundamentales de esta teoría.

El tema seleccionado se enmarca en el campo teórico de la política exterior, entendida tanto como las tendencias generales de comportamiento, como las acciones particulares tomadas por un Estado u otro actor colectivo hacia otros actores colectivos dentro del sistema internacional. La política exterior puede llevarse a cabo utilizando una variedad de instrumentos diferentes, que van desde la adopción de declaraciones, discursos, negociación de tratados, ayuda económica a otros Estados, participación en actividades diplomáticas, como cumbres, y el uso de la fuerza militar (Beach \& Pedersen, 2012). En este caso, las acciones particulares se refieren a los contenidos (discursos, comunicados oficiales, planes de desarrollo) emitidos por los gobiernos brasileros hacia un actor del sistema internacional como la RPC.

Según las leyes vigentes brasileras, los principales tomadores de decisiones de política exterior son el presidente y el ministro de relaciones exteriores (Constituição brasileira, 1988; Decreto 9683, 2019). Por 
tanto, para efectos del presente trabajo, el análisis de las perspectivas de los gobiernos brasileros sobre el gobierno de China se centrará en las perspectivas del presidente y del ministro de relaciones exteriores.

\section{La teoría de rol}

Con el propósito de lograr el objetivo fundamental de este trabajo: analizar la visión de los gobiernos brasileros (2003-2019) hacia el gobierno de China, se evaluaron distintas opciones teóricas del campo de la política exterior. En particular, se tuvieron en cuenta teorías del nivel individual de política exterior como la teoría de rol y los códigos operacionales.

Los códigos operacionales son un conjunto de creencias relacionadas con el mundo político que explican cómo toman decisiones los individuos en materia de política exterior (George, 1969). Para la aplicación de los códigos operacionales es necesario responder a preguntas sobre las creencias filosóficas e instrumentales de los líderes políticos (George, 1969). Dada la cantidad de información necesaria para responder a preguntas tan complejas, los autores decidieron no aplicar los códigos operacionales en este estudio.

Para aplicar los códigos operacionales al caso seleccionado, también se pensó utilizar el software Verbs in Context System (VICS), que analiza cuantitativamente los códigos operacionales de líderes políticos. No obstante, este instrumento solo analiza material en inglés. Dado que el material recolectado estaba mayoritariamente en lengua portuguesa, VICS no ofrecía las herramientas necesarias para el desarrollo de la investigación. Una vez descartado el uso de los códigos operacionales, se explican elementos fundamentales de la teoría de rol.

El concepto de "rol" es tomado del teatro. En ciencias sociales aparece por primera vez en sociología y traza un paralelismo entre los actores que desempeñan un rol teatral y los individuos en entornos sociales, tanto los actores teatrales como los individuos en un determinado entorno social se comportan de manera predecible de acuerdo con un guion (Parlar Dal \& 
Erşen, 2014). En el caso de los actores de teatro, el guion es construido por un dramaturgo, mientras que en el caso de los individuos este es construido socialmente (Parlar Dal \& Erşen, 2014).

En los años setenta, Holsti (1970) adaptó el concepto de "rol" al campo de la política exterior; desde entonces múltiples investigadores en este campo han utilizado esta óptica para sus análisis de política exterior (Harnisch et al., 2011). Ekrem (2015) define "rol" como los comportamientos o las acciones que son adecuadas para un determinado individuo; en el caso de la política exterior, se trata de los comportamientos o las acciones adecuadas para un determinado Estado.

Para Holsti (1970) existen varios tipos de roles en política exterior. National role conception hace referencia a los comportamientos o las acciones que los formuladores de política consideran adecuados para su Estado en el entorno externo (Holsti, 1970). Ego's role conception se refiere a la percepción individual de cuáles son la posición y el comportamiento adecuados para sus funciones (Ekrem, 2015). Finalmente, alter role prescription es la visión de otros frente al individuo; en el caso de la política exterior, se trata de la visión de otros frente a un gobierno concreto (Holsti, 1970).

A través del análisis de contenido y revisando más de 900 fuentes, Holsti (1970) identificó los principales national role conception presentes en el material identificado. En su estudio, Holsti (1970) identificó 17 grandes roles que se repiten en buena medida. Los roles identificados por Holsti (1970) son bastión de la revolución, líder regional, protector regional, activo independiente, partidario de la revolución, defensor de la fe, agente antiimperialista, mediador-integrador, colaborador del subsistema regional, desarrollador, puente, aliado fiel, independiente, ejemplo, desarrollador interno, aislacionista y protegido.

Si bien el interés central de Holsti (1970) fue el análisis de los roles propios percibidos por los principales tomadores de decisiones, el autor no negó la importancia de los alter role prescription. Por tanto, al analizar la visión de los candidatos victoriosos en las elecciones 
presidenciales brasileras de 2003 a 2019 y de sus gobiernos hacia el gobierno de China por medio de la teoría de rol estamos analizando, en términos de Holsti (1970), los alter role prescription percibidos por los gobiernos de Brasil hacia los gobiernos de la RPC.

Si bien en este trabajo se buscaron todos los roles identificados por Holsti (1970), al realizar el análisis del material recolectado bajo la metodología que posteriormente se describirá, se encontró que China (en los casos de los gobiernos del PT) y Taiwán (en el plan de gobierno de Bolsonaro) aparecen principalmente relacionados con los siguientes roles: desarrollador, aliado fiel y ejemplo; además de dos roles creados por los autores del presente trabajo: aliada en la democratización del sistema internacional y aliado exclusivamente comercial. A continuación de explican los roles encontrados en este trabajo:

- Desarrollador: este rol se asigna a un país que coopera en el desarrollo de otros países (Holsti, 1970, p. 266).

- Aliado fiel: este rol se utiliza para definir a un gobierno que se compromete específicamente con apoyar las políticas de otro gobierno (Holsti, 1970, p. 267).

- Ejemplo: aplica a un gobierno que gana prestigio e influencia por la aplicación de ciertas políticas domésticas (Holsti, 1970, p. 267).

Además de los roles explicados, se tuvieron que crear dos roles para explicar la visión de algunos gobiernos brasileros sobre el gobierno chino:

- Aliada en la democratización del sistema internacional: este rol implica la visión de Brasil de percibir a China como aliado en la consolidación de un mundo multipolar y de incluir la voz de ambos países en organizaciones multilaterales.

- Aliado exclusivamente económico/comercial: rol que se asigna a China únicamente como aliado comercial, excluyendo otros temas (como políticos, tecnológicos). 


\section{Metodología}

Con el propósito de cumplir con el objetivo de esta investigación, se sopesaron varias opciones metodológicas. Los académicos han utilizado diferentes opciones metodológicas para la aplicación de la teoría de rol, desde encuestas y entrevistas hasta análisis de contenido, entre otros (Harnisch et al., 2011). En esta investigación en particular, luego de balancear detenidamente varias opciones metodológicas, se decidió realizar análisis cualitativo de contenido para lograr una coherencia entre el marco teórico seleccionado y el diseño metodológico aplicado. Con el propósito de efectuar una observación sistemática del objeto de estudio planteado, se realizó una investigación de tipo cualitativo bajo el método descriptivo, utilizando como técnica de recolección de información el análisis documental de contenido de fuentes primarias.

El análisis cualitativo de contenido es una técnica de investigación que permite el análisis sistemático del significado del material seleccionado a través de codificación (Schreirer, 2012); por tanto, es un método que permite cumplir con el objetivo central de la investigación. La aplicación del análisis cualitativo de contenido permite el análisis de una amplia diversidad de materiales (Schreirer, 2012) desde documentos y discursos oficiales escritos hasta novelas y películas (Duque, 2016). Esto implica que para el análisis cualitativo de contenido no es necesario entrar en contacto personal con quienes producen el material, una ventaja de este método frente a las encuestas y entrevistas.

El análisis de contenido es ampliamente utilizado en los estudios de política exterior (Holsti, 1970; Thies, 2014) y, en particular, en estudios que utilizan teoría de rol. Con esto queda probado que la técnica seleccionada encaja perfectamente con el área de estudio sobre la cual descansa esta investigación: la política exterior.

No existe consenso entre los académicos sobre si el análisis de contenido debe realizarse sobre fuentes primarias o secundarias. Mientras que Holsti (1970) y Wish (1987) usaron fuentes primarias en sus 
investigaciones, Thies (2014) y Walker y Sheldon (1987) realizaron un análisis de contenido de fuentes secundarias. Con el propósito de ser lo más fieles a los contenidos desarrollados por los gobiernos brasileros de 2002 a 2019, en esta investigación solo se realizó análisis de contenido de fuentes primarias publicadas en fuentes oficiales.

En el análisis se incluyeron planes de gobierno, discursos y entrevistas realizados por los presidentes y el ministro de relaciones exteriores entre 2003 y 2019. Si bien la mayoría del material está en portugués, también hay algunos materiales en inglés. Los documentos fueron obtenidos de la página web del Ministerio de Relaciones Exteriores, de la Fundación Alexandre de Gusmão (FUNAG), vinculada al mencionado ministerio, y, en el caso de los planes de gobierno, de las páginas oficiales de los partidos de gobierno. El material fue elegido cualitativamente teniendo en cuenta su disponibilidad e importancia. Se dio prioridad a discursos realizados periódicamente como planes de gobierno (elaborados cada cuatro años), discursos realizados de forma periódica como el discurso ante la Asamblea General de la ONU y los discursos anuales del presidente y del ministro de relaciones exteriores a los diplomáticos graduados del Instituto Rio Branco. Para completar el material, se incluyeron diversos discursos de política exterior disponibles en la página web del Ministerio de Relaciones Exteriores que tratan cuestiones generales de política exterior.

Teniendo en cuenta la metodología utilizada en trabajos similares (Holsti, 1970; Ekrem, 2015), se procuró analizar un mínimo de cinco documentos por año. Para el presente trabajo hay dos excepciones: 2006 y 2019. Para el 2006 se encontró un déficit de material, razón por la cual se analizaron 4 discursos para ese año y no 5. Para 2019 se analizaron 6 contenidos, cuatro del ministro Ernesto Araújo y dos de Bolsonaro. El amplio número de contenidos analizados del ministro Araújo tiene que ver con el hecho de que en el material analizado Bolsonaro hace pocas menciones a la RPC. En total se analizaron 86 contenidos. 
El material recolectado fue analizado a través de codificación y recodificación por medio del software MAXQDA. La codificación se realizó con categorías previamente establecidas (Schreirer, 2014) como los roles identificados por Holsti (1970) y los dos roles nuevos introducidos por los autores de la presente investigación.

El proceso de codificación se realizó individual y grupalmente. En principio, los investigadores realizaron la codificación individualmente. Posteriormente, con el fin de ratificar la validez del proceso de codificación, así como de aprovechar al máximo el material, los participantes del trabajo codificaron las entrevistas en grupo. Una vez que uno de los integrantes codificaba el contenido analizado, lo compartía con los demás miembros del equipo, quienes revisaban la codificación realizada. Finalmente, los miembros del equipo leían y contrastaban los resultados.

\section{Descripción del material seleccionado. Planes de gobierno y discursos ante la Asamblea General de la ONU}

En primer lugar, se recopilaron todos los planes de gobierno de los cuatro presidentes de Brasil entre 2002 y 2019. Los planes de gobierno son documentos en los cuales los candidatos a ejercer un cargo ejecutivo en Brasil informan a los ciudadanos sus principales ideas y propuestas (Politize, 2019). La legislación brasilera obliga a que todos los candidatos a presidente presenten sus propuestas de gobierno consignadas en un plan de gobierno — plano de governo en portugués- (Presidência da República, 1997). Por tanto, estos planes constituyen un contenido propicio para entender las perspectivas de gobierno que proponen los candidatos presidenciales en Brasil.

Para esta investigación se analizaron los planes de gobierno de "Lula" da Silva, Rousseff, Temer y Bolsonaro (tabla 1). 
Tabla 1. Planes de desarrollo de los presidentes electos de Brasil de 2003 a 2018

\begin{tabular}{|l|l|}
\hline \multicolumn{1}{|c|}{ Gobierno } & \multicolumn{1}{c|}{ Nombre del Plan } \\
\hline Luiz Inácio "Lula" da Silva (2003-2007) & Um Brasil para todos \\
\hline Luiz Inácio "Lula" da Silva (2007-2010) & $\begin{array}{l}\text { Lula Presidente. Plano de Governo } \\
\text { 2007-2010 }\end{array}$ \\
\hline Dilma Rousseff (2011-2015) & $\begin{array}{l}\text { Os 13 compromissos programáticos de } \\
\text { Dilma Rousseff para debate na sociedade } \\
\text { brasileira }\end{array}$ \\
\hline Dilma Rousseff (2015-2016) & Mais mudanças, mais futuro \\
\hline Michel Temer (2016-2018) & Uma ponte para o futuro \\
\hline Jair Bolsonaro (2018) & O Camino da prosperidade \\
\hline
\end{tabular}

Fuente: elaboración propia.

Los programas de gobierno en Brasil pueden no ser de obra directa de los presidentes; sin embargo, ese hecho no es tan relevante para el propósito de este capítulo, debido a que más que las perspectivas personales de los futuros presidentes, para los efectos de esta investigación, importa más la perspectiva de gobierno.

Además de los planes de gobierno, los autores del presente trabajo decidieron analizar el contenido de los discursos de política exterior realizados por el presidente y el ministro de relaciones exteriores (tabla 2). Uno de los discursos analizados año por año fue el de los gobiernos brasileros ante la ONU. Una ventaja de analizar estos discursos es que se realizan anualmente, lo que permite comparar la evolución año a año de los mismos. La mayor parte de estos discursos (2002-2011) fueron recopilados por la fundación FUNAG (de Seixas Corrêa, 2012), lo que facilitó la labor de búsqueda para los investigadores.

\footnotetext{
2 Dilma Roussef fue reelegida como presidente de Brasil en 2014; sin embargo, el legislativo brasilero aprobó un juicio político (impeachment) en su contra, por lo que fue removida de su cargo y reemplazada por su vicepresidente, Michel Temer, el 31 de agosto de 2016.

3 Aunque Temer no fue candidato a la presidencia sino candidato a la vicepresidencia en 2014, su partido, el pmdb (Partido Movimiento Democrático Brasilero) sí consignó un programa de gobierno. Tras el juicio político, Temer utilizaría dicho documento para gobernar el país.
} 
Tabla 2. Discursos de Brasil ante la Asamblea General de las ONU

\begin{tabular}{|l|l|l|}
\hline Año & \multicolumn{1}{|c|}{ Vocero de Brasil } & \multicolumn{1}{|c|}{ Cargo } \\
\hline 2003 & Luiz Inácio "Lula" da Silva & Presidente \\
\hline 2004 & Luiz Inácio "Lula" da Silva & Presidente \\
\hline 2005 & Celso Amorim & Ministro de Asuntos Exteriores \\
\hline 2006 & Luiz Inácio "Lula" da Silva & Presidente \\
\hline 2007 & Luiz Inácio "Lula" da Silva & Presidente \\
\hline 2008 & Luiz Inácio "Lula" da Silva & Presidente \\
\hline 2009 & Luiz Inácio "Lula" da Silva & Presidente \\
\hline 2010 & Celso Amorim & Ministro de Asuntos Exteriores \\
\hline 2011 & Dilma Rousseff & Presidente \\
\hline 2012 & Dilma Rousseff & Presidente \\
\hline 2013 & Dilma Rousseff & Presidente \\
\hline 2014 & Dilma Rousseff & Presidente \\
\hline 2015 & Dilma Rousseff & Presidente \\
\hline 2016 & Michel Temer & Presidente \\
\hline 2017 & Michel Temer & Presidente \\
\hline 2018 & Michel Temer & Presidente \\
\hline 2019 & Jair Bolsonaro & Presidente \\
\hline
\end{tabular}

Fuente: elaboración propia.

Además del discurso de los gobiernos a la Asamblea General de la ONU, se incluyeron ocho discursos de los líderes brasileros ante la ONU (tabla 3), recopilados en la investigación de Seixas Corrêa (2012).

Tabla 3. Descripción de contenido y autores de otros discursos analizados

\begin{tabular}{|c|l|}
\hline Año & \multicolumn{1}{c|}{ Autor y nombre del discurso } \\
\hline $2004 a$ & $\begin{array}{l}\text { Luiz Inácio Lula da Silva: "Discurso do Senhor Presidente da República, } \\
\text { Luiz Inácio Lula da Silva, durante reunião da Comissão Mundial sobre a } \\
\text { Dimensão Social da Globalização" }\end{array}$ \\
\hline 2004b & $\begin{array}{l}\text { Luiz Inácio Lula da Silva: Discurso do Senhor Presidente da República, } \\
\text { Luiz Inácio Lula da Silva, na Reunião de Líderes Mundiais para a "Ação } \\
\text { contra a Fome e a Pobreza" }\end{array}$ \\
\hline $2004 c$ & $\begin{array}{l}\text { Luiz Inácio Lula da Silva: "Palavras do Senhor Presidente da República, } \\
\text { Luiz Inácio Lula da Silva, no encerramento da Reunião de Líderes Mundiais } \\
\text { para a "Ação contra a Fome e a Pobreza" }\end{array}$ \\
\hline
\end{tabular}




\begin{tabular}{|c|l|}
\hline Año & \multicolumn{1}{c|}{ Autor y nombre del discurso } \\
\hline 2005 a & $\begin{array}{l}\text { Luiz Inácio Lula da Silva: Discurso do Senhor Presidente da República, } \\
\text { Luiz Inácio Lula da Silva, no Debate de Alto Nível sobre Financiamento ao } \\
\text { Desenvolvimento }\end{array}$ \\
\hline $2005 b$ & $\begin{array}{l}\text { Luiz Inácio Lula da Silva: Discurso do Senhor Presidente da República, } \\
\text { Luiz Inácio Lula da Silva, na Reunião de Cúpula do Conselho de Segurança } \\
\text { das Nações Unidas }\end{array}$ \\
\hline 2005 c & $\begin{array}{l}\text { Luiz Inácio Lula da Silva: Discurso do Senhor Presidente da República, } \\
\text { Luiz Inácio Lula da Silva, por ocasião da Reunião de Alto Nível da } \\
\text { Assembleia Geral das Nações Unidas sobre a Implementação das Metas } \\
\text { do Milênio }\end{array}$ \\
\hline $2008 c$ & $\begin{array}{l}\text { Luiz Inácio Lula da Silva: Encontro especial do Conselho Econômico e } \\
\text { Social das Nações Unidas sobre a crise alimentar mundial }\end{array}$ \\
\hline 2010 & $\begin{array}{l}\text { Ministro de Asuntos Exteriores Ministro Celso Amorim: Cúpula de Chefes } \\
\text { de Estado e de Governo do Conselho de Segurança das Nações Unidas }\end{array}$ \\
\hline
\end{tabular}

Fuente: elaboración propia.

Con el propósito de completar los cinco discursos por año necesarios para el análisis del presente trabajo, se buscaron discursos de política exterior en fuentes como la página oficial del Ministerio de Relaciones Exteriores de Brasil. Se priorizaron discursos que se realizan cada año como los discursos anuales del presidente y del ministro de relaciones exteriores ante los diplomáticos graduados del Instituto Rio Branco o el día del diplomático. El análisis se completó utilizando otros discursos de política exterior, entrevistas y ruedas de prensa incluidos en la página del Ministerio de Relaciones Exteriores.

\section{Presentación de resultados}

\section{Los gobiernos de "Lula" da Silva (2003-2011) y los roles asignados}

Uno de los objetivos principales de la política exterior de los gobiernos del PT es alcanzar la autonomía de Brasil frente al Norte Global, conservando relaciones cordiales con Estados Unidos (Partido dos Trabalhadores, 2002). Para "Lula" da Silva (2012), una relación estrecha con la RPC era un medio para fortalecer la cooperación sur-sur, promover el desarrollo económico y alcanzar la autonomía en materia 
de política exterior. Esto quedó reflejado en el discurso inaugural del presidente brasilero ante la Asamblea General de la ONU en 2003, demostrando que Brasil está dispuesto a establecer un rol de aliado fiel frente a China: "Además de profundizar las relaciones ya muy relevantes con nuestros socios tradicionales de América del Norte y de Europa, buscamos ampliar y diversificar nuestra presencia internacional. En las sociedades con China y Rusia, estamos descubriendo nuevas complementariedades" (da Silva, 2012).

La visión del gobierno "Lula" hacia el gobierno de la RPC fue clara desde la redacción de su Plan de Gobierno 2002. En dicho documento, China es mencionada igual número de veces que América Latina (Partido dos Trabalhadores, 2002). Los principales roles asignados a China durante el gobierno "Lula" son los de ejemplo, desarrollador y, particularmente, el de aliado en la democratización del sistema internacional; a su vez, "Lula" presenta a Brasil como un aliado fiel de la RPC.

El gobierno "Lula" percibió a China como un ejemplo particularmente en materia de desarrollo económico. Según la primera propuesta de gobierno del PT (2002), para la consecución del desarrollo nacional alternativo en Brasil era necesaria la consolidación de un mercado interno, tal como el de China en ese momento. En ese caso puntual, el plan de desarrollo de "Lula" de 2002 presentó el modelo económico chino como ejemplar: "Brasil no debe prescindir de las empresas, tecnología y capital extranjeros (...) Los países que hoy tratan de desarrollar mercados internos, como India y China, no lo hacen de espalda al mundo, descartando capitales y mercados externos" (Partido dos Trabalhadores, 2002).

La visión de la RPC como ejemplo en materia de desarrollo económico fue más allá del primer plan de desarrollo de "Lula" (Partido dos Trabalhadores, 2002) y estuvo presente en otros materiales tanto del primer como del segundo gobierno:

Aunque los países desarrollados aún dominen los flujos comerciales mundiales (...) los países en desarrollo, incluyendo ahí a 
China, pasaron en diez años de $28 \%$ a $38 \%$ de las exportaciones mundiales. Este cambio es atribuible, en gran medida, a las nuevas economías industriales, China a la cabeza (Amorim, 2007a).

La visión de China como un ejemplo en materia económica y de desarrollo va de la mano con otro de los roles más asignados a la RPC durante el gobierno "Lula": el de desarrollador. Dado el crecimiento económico de China y la cercanía que Brasil propone tener hacia el gigante asiático, resulta natural que la RPC sea una aliada en el desarrollo de Brasil: "Dedicamos atención especial a nuestra relación con la República Popular de China. China fue el tercer mayor mercado para nuestras exportaciones" (Amorim, 2004). El rol más repetido del gobierno "Lula" hacia la RPC implicó ver al gigante asiático como un aliado en la democratización del sistema internacional: "Brasil continúa trabajando para impulsar una reforma que otorgue al Consejo de Seguridad una mayor legitimidad, eficacia y representatividad (...) Con otros tres países en desarrollo que también integran ese ejercicio: Suráfrica, China e India" (Amorim, 2007b).

Nuestro gobierno conducirá una aproximación de países de importancia regional, como Suráfrica, India, China y Rusia. Se trata de construir sólidas relaciones bilaterales y articular esfuerzos con el fin de democratizar las relaciones internacionales y los organismos multilaterales como la Organización de las Naciones Unidas (ONU), el Fondo Monetario Internacional, la Organización Mundial del Comercio (OMC) y el Banco Mundial (Partido dos Trabalhadores, 2002).

El gobierno de "Lula" también percibió a grupos como el BRICS como un instrumento para profundizar esa democratización del sistema internacional:

Poco a poco va siendo descartado el viejo alineamiento conformista de los países del Sur con los centros tradicionales. Esa nueva actitud no conduce, por lo pronto, a una postura de confrontación. Simplemente por medio del diálogo directo, sin intermediación de las grandes potencias, los países en desarrollo 
se han acreditado para cumplir un nuevo papel en el diseño de un mundo multipolar. Basta citar iniciativas como (...) el G-20 (...) y la articulación de los BRICS (da Silva, 2012, p. 934).

\section{Los gobiernos de Dilma Rousseff (2011-2016)}

La política exterior del gobierno de Rousseff implicó una continuidad con la política exterior de "Lula" da Silva, en ese sentido, el propósito de alcanzar una política exterior brasilera autónoma frente al Norte Global siguió presente (Partido dos Trabalhadores, 2009). Por esta razón, China fue visto como un aliado fiel de Brasil. Esta alianza fue fundamental para consolidar tanto la autonomía y soberanía de Brasil en el sistema internacional, como para proyectar valores políticos del Brasil del PT en este sistema:

Brasil adopta una política exterior soberana: defiende los principios históricos de nuestra diplomacia, respetando la autodeterminación y la política de no intervención (...) Y sobre todo, por la lucha incansable por la paz mundial; amplía su presencia internacional, combatiendo el hambre y la pobreza en el mundo y promoviendo la solidaridad entre los países pobres y en desarrollo... fortaleciendo las relaciones Sur-Sur, especialmente con (...) China (Partido dos Trabalhadores, 2009).

Dada la continuidad de la política exterior de Rousseff frente a "Lula" da Silva, de 2011 a 2014, los roles asignados por los ministros de relaciones exteriores y por la propia presidente hacia el gobierno de China siguieron una línea simimlar a los de "Lula" da Silva, en primer lugar, como aliado en la democratización del sistema internacional y, en segundo lugar, como desarrollador y ejemplo: "La recién concluida cúpula de los BRICS, en China, reafirmó el objetivo de los grandes países emergentes por un orden internacional más democrático y representativo del siglo xx" (Rousseff, 2011):

Nuestra visión para el sur del mundo, esa política que enfatiza esa característica Sur-Sur como camino marcado por un repudio a todas las formas de dominio y de opresión entre los países explica 


\section{0 / Angelo Flórez de Andrade - Carlos Alberto Chaves García}

también el énfasis que dimos a las relaciones con los países que tienen la misma visión que Brasil, países continentales que también emergerán para el desarrollo como es el caso de los países BRICS (Rousseff, 2013).

Sin embargo, a partir de 2014, cuando Brasil entró en recesión (World Bank, 2020), tanto la presidente como sus ministros de relaciones exteriores empezaron a asignar a China roles más relacionados con la economía y el comercio como desarrollador y aliado económico y comercial, sin que el rol de aliado en la democratización del sistema internacional desapareciera:

El plan de acción conjunta 2015-2021, y los acuerdos, varios y múltiples que firmamos hoy, son una prueba de la amplitud y ambición de nuestra agenda. En la esfera bilateral hemos cooperado en áreas tan diversas como la exploración de petróleo de Presal, en la cual China dio una gran contribución (Rousseff, 2015a).

\section{El gobierno de Temer (2016-2018)}

$\mathrm{Al}$ analizar el plan de desarrollo del gobierno Temer, los discursos y entrevistas seleccionados, es evidente que existe un cambio general de la política exterior brasileña que pasa por un acercamiento hacia EE. UU. y los países europeos, así como una apuesta por promover a Brasil como un destino de inversión internacional (Actis, 2017).

El mencionado cambio de orientación en la política exterior brasileña del gobierno Temer se reflejó en los roles que asignó este gobierno a la RPC. Si bien los roles relacionados con temas económicos, comerciales y de desarrollo (y en particular desarrollador, aliado exclusivamente económico y ejemplo) continuaron presentes, el rol de aliado en la democratización del sistema internacional casi desaparece. Este cambio en el rol dado a la RPC puede explicarse a partir de la mayor vinculación buscada por el gobierno Temer con el gobierno de EE. UU. a nivel comercial pero también en otras agendas como el sector defensa, ${ }^{4}$

4 Durante el gobierno de Temer se firmaron acuerdos relevantes como el Acuerdo de 
la conducción de la politica regional y la participación de Brasil en el ámbito multilateral. Esto reflejó una alianza politica con Washington combinada con una percepción de China como socio comercial clave, pero no como aliado político estelar.

El gobierno Temer consideraba que la relación con la RPC significaba para Brasil una oportunidad de crecimiento económico, veían al gigante asiático como un desarrollador y como un aliado exclusivamente económico y comercial:

Vale la pena destacar la creciente escena de inversiones chinas en capital de riesgo, el llamado Venture capital que es fundamental para el financiamiento de startups. Esos capitales chinos demuestran creciente interés en la escena emprendedora brasilera (Nunes, 2017).

La diplomacia de la innovación (...) constituye una herramienta importante para aportar elementos externos que pueda fomentar la competitividad nacional y ayudar a integrar a Brasil en las cadenas globales de producción más avanzadas (...) Europa pretende invertir en la industria (...) más de 1.3 trillones de euros- China 1.8 trillones de euros (Nunes, 2017).

Este cambio de orientación de política exterior también implicó un cambio de percepción hacia el BRICS, a los cuales también asigna roles cercanos a temas económicos y de desarrollo (desarrollador y aliado exclusivamente económico/comercial):

Y revitalizamos o iniciamos negociaciones comerciales con socios de todas las regione - Unión Europea, Asociación Europea de Libre Comercio, Canadá, Corea del Sur, Singapur, Lỉbano, Marruecos, Túnez (...) Especialmente productiva ha sido nuestra participación en foros de cooperación como el G20, los BRICS (...) Son

Intercambio de Información sobre Investigación y Desarrollo (MIEA) y se evidenció el fortalecimiento del comercio bilateral del sector Defensa a través de mecanismos como el "Diálogo entre las Industrias de Defensa de Brasil y EE. UU". 
espacios donde producimos resultados concretos, con impacto directo para nuestras sociedades (Temer, 2018a).

Finalmente, vale la pena destacar que el gobierno Temer no evidenció referencias directas a Taiwán, apoyando así la política de una sola China.

\section{El gobierno Bolsonaro (2018 en adelante)}

Durante su carrera política, Jair Bolsonaro se ha presentado como la antítesis de la izquierda (Solano Gallego, 2018). En este sentido, para Bolsonaro los gobiernos del PT implicaron épocas oscuras para Brasil: "Mi país estuvo muy próximo del socialismo, lo que nos situó en una situación de corrupción generalizada, grave recesión económica, altas tasas de criminalidad y de ataques ininterrumpidos contra los valores familiares y religiosos" (Bolsonaro, 2019).

Este rechazo hacia la izquierda política se ve reflejado también en su visión sobre la RPC. Como se mencionó anteriormente, Bolsonaro demostró desconfianza e incluso repudio hacia el gobierno de la RPC durante su campaña electoral (Lapper, 2019). El candidato llegó a romper la tradición brasilera establecida desde 1974 de apoyar la política de "una sola China". En campaña, Bolsonaro desplazó los roles de aliado fiel y ejemplo a seguir de la RPC hacia Taiwán.

En su programa de gobierno (Bolsonaro, 2018) no se hicieron referencias directas ni a la RPC ni al BRICS; no obstante, hay cuatro referencias a Taiwán. En la primera mención a Taiwán, Bolsonaro recordó a los electores su visita a la isla de Formosa. En esa misma mención, se presentó a Taiwán en un rol de modelo a seguir, en esta ocasión como modelo educativo: "La estrategia educativa de Japón, Taiwán y Corea del Sur, países recientemente visitados por Jair Bolsonaro, tuvo un papel clave en el desarrollo económico y social. En una generación, países pobres se convirtieron en ricos" (Bolsonaro, 2018).

En la segunda y tercera menciones del programa de gobierno de Bolsonaro, Taiwán fue presentado como modelo de desarrollo 
tecnológico a seguir. En esta ocasión, la campaña Brasil Acima de Tudo (Bolsonaro, 2018) recordó a los electores que Bolsonaro visitó personalmente Taiwán:

El modelo actual de investigación y desarrollo en Brasil está totalmente agotado (...) Estados Unidos, Israel, Taiwán, Corea del Sur y Japón incentivan estrategias descentralizadas (...) Esto genera riqueza, bienestar y desarrollo para todos. Jair Bolsonaro puede constatar eso personalmente. En todos los países visitados hay tal tipo de centros. Inclusive en los países que han liderado tal dinámica, Japón, Taiwán y Corea del Sur, hay un gran énfasis en cursos técnicos y carreras (de ciencias) exactas.

Luego de casi un año del gobierno de Bolsonaro, Nogueira Galinairi (2019) identificó varios ejes de la política exterior brasilera: 1) alineamiento con EE. UU., 2) distanciamiento de algunos aliados de los gobiernos del PT; 3) aproximación a gobiernos de derecha y extrema derecha, y 4) crítica del multilateralismo y la integración regional, entre otros. Adicionalmente a los puntos nombrados, Bolsonaro también modificó la postura del gobierno brasilero frente a la crisis política venezolana, abandonando Unasur e ingresando al Grupo de Lima "que se identifica más como una instancia útil en términos de política de contención del régimen chavista" (Chaves Garcia \& Ortiz Morales, 2019).

De todos estos puntos, al menos tres afectan la relación entre Brasil y China. Particularmente el alineamiento con los EE. UU. de Donald Trump - más aún en el contexto de guerra comercial entre EE. UU. y China-, el distanciamiento con los aliados internacionales del PT y la crítica al multilateralismo (Malamud, 2018).

A pesar de la agresiva retórica de Bolsonaro hacia China durante su campaña presidencial y de su admiración a la política exterior de Trump (Malamud, 2018), los resultados del material analizado arrojaron que el gobierno Bolsonaro ha cambiado, al menos 
mayoritariamente, ${ }^{5}$ los roles asignados hacia la RPC. Desde el ascenso al poder de Bolsonaro la RPC aparece en discursos oficiales con roles como aliado exclusivamente económico y comercial. Prueba de ello es el discurso de Bolsonaro (2019) ante la ONU:

A lo largo de este año, establecimos una amplia agenda internacional con la intención de rescatar el país de Brasil en el escenario mundial (...) Esas visitas reforzarán la amistad y profundización de las relaciones con Japón, China, Arabia Saudí, Emiratos Árabes y Qatar.

El ministro de relaciones exteriores, Ernesto Araújo, también ha reflejado este cambio, presentando a China como un aliado exclusivamente económico/comercial, pormenorizando la agresiva retórica de campaña:

Nunca hubo fricción con China. Hubo interpretaciones de una declaración que di que podrían resultar en un problema, lo que nunca se materializó. Mi visión coincide con la de todo el gobierno: China es un aliado económico de primera línea, con el cual queremos no solo continuar sino aumentar negocios (Araújo, 2019).

Brasil se ha beneficiado mucho del comercio con China, siendo algo negativo en términos de algunos sectores que perdimos por la competitividad china, pero nuevamente nada contra China, eso es solo un reconocimiento de su éxito y algunos de nuestros fracasos (...) Lo que queremos es realizar una serie de negociaciones donde cada uno tenga sus tarjetas y tratemos de llegar a un resultado beneficioso común. Así que no veo nada en este tipo de relación de confrontación con China, creo que también es

\footnotetext{
5 Aunque Jair Bolsonaro, el canciller Ernesto Araújo y el vicepresidente Hamilton Mourão han modificado, al menos en público, los roles asignados a la RPC, otros personajes cercanos al gobierno como el hijo del presidente, Eduardo Bolsonaro, y el exministro de educación, Abraham Weintraub, han hecho declaraciones desafortunadas y agresivas sobre el gobierno de la RPC (Benites, 2020).
} 
una relación de cooperación que puede venir en beneficio mutuo (Araújo \& Ministério das Relações Exteriores, 2019).

El gobierno Bolsonaro no solo ha desescalado su retórica de desconfianza hacia China; de hecho, su gobierno ha continuado realizando las Cosban (Ministério das Relações Exteriores, 2019) y el mismo presidente Bolsonaro realizó una visita oficial a China (Ministério das Relações Exteriores, 2019).Todo indica que este cambio de estrategia frente a China corresponde a que varios miembros del gobierno comprenden la importancia que tiene China en términos económicos y comerciales para Brasil.

Basta revisar la agenda de trabajo de la visita oficial de Bolsonaro a China para comprobar que el líder brasilero privilegia los temas comerciales sobre los temas políticos, tecnológicos o educativos (Ministério das Relações Exteriores, 2019). Siete de los ocho instrumentos de cooperación firmados entre ambas partes tienen que ver con comercio, el otro restante con temas educativos (Ministério das Relações Exteriores, 2019). Este trabajo demostró cómo esa visión exclusivamente comercial se refleja en la asignación de China como aliado exclusivamente comercial/económico, rol pertinente y propuesto por los autores del presente trabajo.

\section{Conclusión}

En el presente trabajo se identificaron cuatro etapas diferentes en las cuales los gobiernos brasileros cambiaron su visión principal del rol asignado a China. La tabla 4 sintetiza los resultados encontrados.

Tabla 4. Resumen de roles por gobiernos

\begin{tabular}{|c|c|l|}
\hline $\begin{array}{c}\text { Candidatos presidenciales } \\
\text { vencedores / presidentes }\end{array}$ & $\begin{array}{c}\text { Periodo } \\
\text { analizado }\end{array}$ & \multicolumn{1}{c|}{ Roles asignados a China } \\
\hline "Lula" da Silva y Dilma Rousseff & $2002-2014$ & $\begin{array}{l}\text { Rol principal: aliado en la } \\
\text { democratización del sistema } \\
\text { internacional. } \\
\text { Otros roles: desarrollador y } \\
\text { ejemplo. }\end{array}$ \\
\hline
\end{tabular}


26 / Angelo Flórez de Andrade - Carlos Alberto Chaves García

\begin{tabular}{|l|l|l|}
\hline $\begin{array}{c}\text { Candidatos presidenciales } \\
\text { vencedores / presidentes }\end{array}$ & $\begin{array}{c}\text { Periodo } \\
\text { analizado }\end{array}$ & \multicolumn{1}{c|}{ Roles asignados a China } \\
\hline Dilma Rousseff & 2014-2016 & $\begin{array}{l}\text { Rol principal: desarrollador y } \\
\text { ejemplo. } \\
\text { Otros roles: aliado en la } \\
\text { democratización del sistema } \\
\text { internacional. }\end{array}$ \\
\hline Michel Temer & $2016-2018$ & $\begin{array}{l}\text { Rol principal: aliado exclusivamente } \\
\text { económico/ comercial y } \\
\text { desarrollador. } \\
\text { Otros roles: No hay. }\end{array}$ \\
\hline Jair Bolsonaro & $2018-2020$ & $\begin{array}{l}\text { Roles principales como candidato: } \\
\text { evade la relación con China, } \\
\text { percibe a Taiwán como ejemplo y } \\
\text { aliado fiel. } \\
\text { Roles principales del gobierno: } \\
\text { aliado exclusivamente económico/ } \\
\text { comercial }\end{array}$ \\
\hline
\end{tabular}

Fuente: elaboración propia.

La investigación hizo evidente que mientras que los candidatos "Lula" da Silva, Rousseff y Temer no modificaron profundamente los roles asignados a la RPC en campaña con respecto a los roles asignados durante el gobierno. Por el contrario, el gobierno Bolsonaro modificó considerablemente su visión sobre la RPC con respecto a su postura como candidato.

Luego de la revisión del material seleccionado se observó que tanto los gobiernos de "Lula" da Silva como de Rousseff promovieron una política exterior que le permitiría a Brasil una mayor autonomía con respecto al Norte Global. Para lograr esa autonomía fue necesario promover el desarrollo económico de Brasil, reducir la dependencia frente a EE. UU. e impulsar la democratización del sistema internacional para hacer que Brasil pudiese servir como vocero del Sur Global (da Silva, 2012).

Los gobiernos "Lula" da Silva y Rousseff consideraron que acercarse a la RPC implicaba una herramienta para lograr la autonomía en materia de política exterior, la promoción del desarrollo económico de 
Brasil, la reducción de la dependencia frente a EE. UU. y el impulso de la democratización del sistema internacional. Por eso no es de extrañar que entre 2002 y 2014 el rol más identificado en el material asignado por los gobiernos brasileros a China hubiera sido el de aliado en la democratización del sistema internacional, seguido por los de desarrollador y ejemplo.

El análisis del material arroja que, a partir de 2014, año en el que Brasil comenzó un periodo de recesión económica, el gobierno brasilero empezó a asignar un mayor número de veces al gobierno de China roles más relacionados con temas económicos y comerciales sin dejar de asignarle el rol de aliado en la democratización del sistema internacional.

Tras la destitución de Dilma Rousseff en agosto de 2016, el gobierno Temer alteró la politica exterior brasilera frente al periodo de "Lula" da Silva, intensificó el acercamiento a EE. UU., lo cual implicó la necesaria resignificación de la relación con la RPC. Atrás quedaron las referencias a China como aliado en la democratización del sistema internacional. Bajo el gobierno Temer, China pasó a ser percibida como un importante socio con el cual el "nuevo Brasil" profundizaría sus relaciones comerciales (Temer, 2018a).

La visión política antiizquierdista de Jair Bolsonaro impregnó todas sus propuestas de campaña, incluida la política exterior. Así, en su programa de gobierno, Bolsonaro evitó mencionar la RPC, pero sí mencionó numerosas veces a Taiwán, rompiendo con la tradición brasilera de respetar el principio de "una sola China" y evitó pronunciarse sobre el gobierno de Formosa (Bolsonaro, 2018). El programa de gobierno de Bolsonaro refleja una percepción de rol hacia Taiwán de aliado fiel y ejemplo a seguir.

A pesar de la retórica de campaña, el gobierno Bolsonaro ha modificado los roles que asigna a China, pasando a asignarle roles de aliado exclusivamente económico y comercial. Tal vez la frase que mejor resuma la actitud del gobierno Bolsonaro frente a China sea la del ministro de economía: China es ese tipo que usted sabe que debe 
aguantar, porque por cada dólar que Brasil exporta a Estados Unidos, exporta tres a China (Alessi, 2020).

El tiempo dirá si Bolsonaro decide profundizar los lazos comerciales con China y si su estrategia resulta adecuada. Vale la pena preguntarse cómo el gobierno manejará los temas de cooperación política con China, además de otros temas de la agenda COSBAN y del PAC como la cooperación educativa, tecnológica y cultural, entre otros.

Además de aportar al estudio de la política exterior brasilera, así como al análisis de la relación sino-brasilera, este artículo aporta nuevos elementos para el estudio de la teoría de rol con el descubrimiento de dos nuevos roles: aliado en la democratización del sistema internacional y aliado exclusivamente económico/comercial. Estos nuevos roles podrán ser utilizados en próximos estudios en el terreno de la política exterior. Con seguridad, estos dos nuevos roles podrán ser aplicados a estudios que van más allá de la visión de los gobiernos brasileros sobre China.

\section{Referencias}

Actis, E. (31 de agosto de 2017). La política exterior de Michel Temer. Profundización de un ajuste ya iniciado. Foreign Affairs Latinoamérica. http://revistafal.com/la-politica-exterior-de-michel-temer/

Alessi, G. (22 de mayo de 2020). "Guedes: “China é aquele cara que você sabe que tem que aguentar"». El País. Recuperado de https://brasil. elpais.com/brasil/2020-05-23/guedes-china-e-aquele-cara-que-vocesabe-que-tem-que-aguentar.html

Almagro Castro, D. (2018). ¿Juicio legítimo o golpe de Estado encubierto? El impeachment a la Presidenta de la República Federal de Brasil, Dilma Rousseff. Revista Derecho del Estado, (42), 25-50. https://doi. org/10.18601/01229893.n42.02

Amorim, C. (2004). Palestra do Ministro de Estado das Relaçôes Exteriores, Embaixador Celso Amorim, na Federação de Indústrias de Minas Gerais. Recuperado de https://www.gov.br/mre/pt-br/centrais-de-conteudo/ publicacoes/discursos-artigos-e-entrevistas/ministro-das-relacoes- 
-exteriores/discursos-mre/palestra-do-ministro-de-estado-das-relacoes-exteriores-embaixador-celso-amorim-na-federacao-de-industrias-de-minas-gerais

Amorim, C. (28 de agosto de 2007a). Discurso do Ministro Celso Amorim por ocasião do Seminário do TCU sobre Politica do Comércio Exterior Brasileiro (texto base). Recuperado de https://www.gov.br/mre/pt-br/ centrais-de-conteudo/publicacoes/discursos-artigos-e-entrevistas/ ministro-das-relacoes-exteriores/discursos-mre/discurso-do-ministro-das-relacoes-exteriores-embaixador-celso-amorim-no-seminario-do-tcu-sobre-politica-do-comercio-exterior-brasileiro-texto-base-brasilia-df-28-08-2007

Amorim, C. (5 de noviembre de 2007b). Palestra proferida pelo Ministro Celso Amorim por ocasião da II Conferência Nacional de Politica Externa e Politica Internacional. Recuperado de https://www.gov.br/mre/pt-br/ centrais-de-conteudo/publicacoes/discursos-artigos-e-entrevistas/ ministro-das-relacoes-exteriores/discursos-mre/palestra-proferida-pelo-ministro-de-estado-das-relacoes-exteriores-embaixador-celso-amorim-por-ocasiao-da-ii-conferencia-nacional-de-politica-externa-e-politica-internacional-rio-de-janeiro-rj-05-11-2007

Amorim, C. (2010). Ministro de Asuntos Exteriores Ministro Celso Amorim: Cúpula de Chefes de Estado e de Governo do Conselho de Segurança das Nações Unidas. En S. E. Moreira Lima, Brasile China. 40 anos de relações diplomáticas. Análises e documentos (pp. 953-957). Fundação Alexandre de Gusmão (FUNAG).

Araújo, E. (11 de Septiembre de 2019). "Brazil is back" - Discurso do na Heritage Foundation - Washington, 11 de setembro de 2019. Recuperado de http://www.itamaraty.gov.br/pt-BR/discursos-artigos-e-entrevistas-categoria/ministro-das-relacoes-exteriores-discursos/20880-brazil-is-back-discurso-do-ministro-das-relacoes-exteriores-na-heritagefoundation-washington-11-de-setembro-de-2019-original-em-i

Beach, D., \& Pedersen, R. B. (2012). Analyzing foreign policy. Red Globe Press. Benites, A. (19 de marzo de 2020). Esforço de Eduardo Bolsonaro para demonizar China copia Trump e ameaça elo estratégico do Brasil. El País Brasil. Recuperado de https://brasil.elpais.com/brasil/2020-03-19/esforco-de-eduardo-bolsonaro-para-demonizar-chinacopia-trump-e-ameaca-elo-estrategico-do-brasil.html 
Bolsonaro, J. (2018). O caminho da prosperidade. Proposta de Plano de Governo. https://flaviobolsonaro.com/PLANO_DE_GOVERNO_JAIR_BOLSONARO_2018.pdf Bolsonaro, J. (27 de septiembre de 2019). Discurso do presidente Jair Bolsonaro na abertura da $74^{a}$ Assembleia Geral das Nações Unidas. Recuperado de https://www.gov.br/mre/pt-br/centrais-de-conteudo/publicacoes/discursos-artigos-e-entrevistas/presidente-da-republica/presidente-da-republica-federativa-do-brasil-discursos/ discurso-do-presidente-jair-bolsonaro-na-abertura-da-74-assembleia-geral-das-nacoes-unidas-nova-york-24-de-setembro-de-2019

Brasil, Presidencia da República. (1988). Constitução da República Federativa do Brasil. Recuperado de http://www.planalto.gov.br/ccivil_03/constituicao/constituicao.htm

Brasil, Presidencia de la República. Decreto 9683, Aprova a Estrutura Regimental e o Quadro Demonstrativo dos Cargos em Comissão e das Funções de Confiança do Ministério das Relações Exteriores, remaneja cargos em comissão e funções de confiança e transforma Funções Comissionadas do Poder Executivo - FCPE (9 de enero de 2019). Recuperado de http://www.planalto.gov.br/ccivil_03/_ato2019-2022/2019/ decreto/D9683.htm

Brasil de Holanda, F. M. (2016). 40 anos das relações Brasil-China: de onde viemos, onde estamos, para onde vamos. En S. E. Moreira Lima (Org.), Brasile China. 40 anos de relações diplomáticas. Análises e documentos (pp. 35-56). Fundação Alexandre de Gusmão (FUNAG).

Cardoso, F. H. (2016) Discurso do Senhor Presidente da República, Fernando Henrique Cardoso, por ocasião da Visita Oficial à República Popular da China. (2016). En S. E. Moreira Lima, Brasil e China. 40 anos de relações diplomáticas. Análises e documentos (pp. 275-278). Fundação Alexandre de Gusmão (FUNAG).

Chaves Garcia, C., \& Ortiz Morales, C. (2019). Grupo de Lima: ¿expresión renovada del multilateralismo latinoamericano? En Autores, Nuevas propuestas de integración regional: tendencias y retos de transformación (pp. 197-247). Universidad Cooperativa de Colombia.

Costa, A., \& Soares Nogara, T. (2020). Evolución y ejes de la política exterior brasileña contemporánea. Anuario Internacional CIDOB, 248-256. Recuperado de https://www.cidob.org/articulos/anuario_internacional_cidob/2020/evolucion_y_ejes_de_la_politica_exterior_brasilena_contemporanea 
Duque, M. (2016). The rascals paradise. Brazilian national identity in 2010. En T. Hopf, \& B. Allan (Eds.), Making identity count: Building a national identity database (pp. 47-63). Oxford University Press.

Ekrem, B. (2015). Shift-of-axis in Turkish foreign policy: Turkish national role conceptions before and during AKP rule. Turkish Studies, 16(3), 291-309. https://doi.org/10.1080/14683849.2015.1050958

Esteban, M. (2005). Las relaciones entre China y Taiwán: tendencias y propuestas. Recuperado de http://www.realinstitutoelcano.org/wps/portal/ rielcano_es/contenido/!ut/p/a1/04_Sj9CPykssy0xPLMnMz0vMAfGjzOKNQ1zcA73dDQ38_YKNDRwtfN1cnf2cDf1DjfULsh0V Aepxmvs!/?WCM_GLOBAL_CONTEXT=/elcano/Elcano_es/ Zonas_es/ARI\%2026-2005

Frenkel, A., \& Azzi, D. (2019). Cambio y ajuste: la política exterior de Argentina y Brasil en un mundo en transición (2015-2017). Colombia Internacional (96), 177-207. https:/ / doi.org/10.7440/colombiaint96.2018.07

George, A. (1969). The "operational code": A neglected approach to the study of political leaders and decision-making. International Studies Quarterly, 13(2), 190-222. https://doi.org/10.2307/3013944

Harnisch, S., Frank, C., \& Maull, H. (2011). Role theory in international relations approaches and analyses. Routledge.

Holsti, K. (1970). National role conceptions in the study of foreign policy. International Studies Quarterly, 14(3), 233-309. https://doi. org $/ 10.2307 / 3013584$

Lapper, R. (2019). Bolsonaro tenía a China en la mira. Pero la realidad lo desafió. Americas Quarterly, 13(2). Recuperado de https://www.americasquarterly.org/article/bolsonaro-took-aim-at-china-then-reality-struck/

Malamud, C. (2018). ¿Qué política exterior tendrá Brasil? Recuperado de http://www.realinstitutoelcano.org/wps/portal/rielcano_es/ contenido?WCM_GLOBAL_CONTEXT=/elcano/elcano_es/zonas_es/ari119-2018-malamud-que-politica-exterior-tendra-brasil

Brasil, Ministério das Relações Exteriores. (24 de octubre de 2019). Visita de Estado do do Presidente da República, Jair Bolsonaro, a Pequim (China). Recuperado de http://www.itamaraty.gov.br/images/2019/Fact_ Sheet_Visita_PR_a_China_out2019.pdf

Brasil, Ministério das Relações Exteriores. (12 de abril de 2011). Visita de Estado da Presidenta da República, Dilma Rousseff, à República Popular da China. Recuperado de https://www.gov.br/mre/es/canales_servicio/ 
prensa/notas-a-la-prensa/visita-de-estado-de-la-presidenta-de-la-republica-dilma-rousseff-a-la-republica-popular-de-china-pekin-12-y-13-de-abril-de-2011

Brasil, Ministério das Relações Exteriores. (14 de marzo de 2019). Brasil-China: Reunião da Comissão Sino-brasileira de Alto Nível de Concertação e Cooperação (COSBAN) - 14 de março de 2019. Recuperado de https:// www.gov.br/mre/pt-br/canais_atendimento/imprensa/notas-a-imprensa/2019/brasil-china-reuniao-da-comissao-sino-brasileira-de-alto-nivel-de-concertacao-e-cooperacao-cosban-14-de-marco-de-2019

Brasil, Ministério das Relações Exteriores. (2 de diciembre de 2019). República Popular da China. Recuperado de http:/ / antigo.itamaraty.gov.br/ es/ficha-pais/5989-republica-popular-china

Nogueira Galinari, T. (2019). A “Guinada à direita” e a nova política externa brasileira. Caderno de Geografia, 29(Número Especial 2), 190-212. https://doi.org/10.5752/P.2318-2962.2019v29n2p190-211

Nunes, A. (7 de marzo de 2017a). Texto-basepara o discurso de posse do Ministro de Estado das Relações Exteriores, Aloysio Nunes Ferreira. Recuperado de https://www.gov.br/mre/pt-br/centrais-de-conteudo/publicacoes/ discursos-artigos-e-entrevistas/ministro-das-relacoes-exteriores/ discursos-mre/texto-base-para-o-discurso-de-posse-do-ministro-de-estado-das-relacoes-exteriores-aloysio-nunes-ferreira-palacio-itamaraty-7-de-marco-de-2017

Nunes, A. (12 de junio de 2017b). Discurso do ministro Aloysio Nunes Ferreira por ocasião das comemorações dos 30 anos da Agência Brasileira de Cooperação (ABC). Recuperado de https://www.gov.br/mre/pt-br/centrais-de-conteudo/ publicacoes/discursos-artigos-e-entrevistas/ministro-das-relacoes-exteriores/discursos-mre/discurso-do-ministro-aloysio-nunes-ferreira-por-ocasiao-das-comemoracoes-dos-30-anos-da-agencia-brasileira-de-cooperacao-abc

Nunes, A. (20 de julio de 2017c). Palavras do Senhor Ministro de Estado, Aloysio Nunes Ferreira, por ocasião da abertura da XXII Reunião Ordinária do Conselho de Ministros da CPLP. Recuperado de https://www.gov.br/mre/pt-br/ centrais-de-conteudo/publicacoes/discursos-artigos-e-entrevistas/ ministro-das-relacoes-exteriores/discursos-mre/palavras-do-senhor-ministro-de-estado-aloysio-nunes-ferreira-por-ocasiao-da-abertura-da-xxii-reuniao-ordinaria-do-conselho-de-ministros-da-cplp-brasilia-20-de-julho-de-2017 
Parlar Dal, E. \& Erşen, E. (2014). Reassessing the "Turkish Model" in the Post-Cold War Era: A role theory perspective. Turkish Studies, 15(2), 258-282.

Brasil, Partido dos Trabalhadores. (2002). Programa de Governo 2002 coligação Lula Presidente. Um Brasil para todos. Fundação Perseu Abramo.

Brasil, Presidência da República. Lei 9.504, Estabelece normas para as eleições (30 de septiembre de 1997). Recuperado de http://www.planalto. gov.br/ccivil_03/leis/19504.htm

Rosseff, D. (1 de enero de 2011). Pronunciamento da Presidenta da República, Dilma Rousseff, à Nação Brasileira, no Parlatório do Palácio do Planalto. Recuperado de https://www.gov.br/mre/pt-br/centrais-de-conteudo/ publicacoes/discursos-artigos-e-entrevistas/presidente-da-republica/ presidente-da-republica-federativa-do-brasil-discursos/pronunciamento-da-presidenta-da-republica-dilma-rousseff-a-nacao-brasileira-no-parlatorio-do-palacio-do-planalto

Rousseff, D. (24 de septiembre de 2014). Discurso proferido pela Presidenta da República, Dilma Rousseff, na abertura do Debate de Alto Nivel da 69a Assembleia Geral das Nações Unidas (ONU). Recuperado de https://www.gov.br/mre/pt-br/centrais-de-conteudo/publicacoes/discursos-artigos-e-entrevistas/presidente-da-republica/ presidente-da-republica-federativa-do-brasil-discursos/discurso-proferido-pela-presidenta-da-republica-dilma-rousseff-na-abertura-do-debate-de-alto-nivel-da-69-assembleia-geral-das-nacoes-unidas-onu-nova-york-24-de-setembro-de-2014

Rousseff, D. (20 de abril de 2011). Discurso da Presidenta da República, Dilma Rousseff, por ocasião de formatura da Turma 2009-2011 do Instituto Rio Branco. Recuperado de https:/ /www.gov.br/mre/pt-br/ centrais-de-conteudo/publicacoes/discursos-artigos-e-entrevistas/ presidente-da-republica/presidente-da-republica-federativa-do-brasil-discursos/discurso-da-presidenta-da-republica-dilma-rousseff-na-cerimonia-de-formatura-da-turma-2009-2011-do-instituto-rio-branco

Rousseff, D. (abril de 2012). Discurso da Presidenta da República, Dilma Rousseff, por ocasião de formatura da Turma de 2010-2012 do Instituto Rio Branco. Recuperado de http://www.itamaraty.gov.br/pt-BR/ discursos-artigos-e-entrevistas-categoria/presidente-da-republica-federativa-do-brasil-discursos/4697-discurso-da-presidenta-da-re- 
publica-dilma-rousseff-na-cerimonia-de-formatura-da-turma-de-2010-2012-do-instituto-rio-bra

Rousseff, D. (20 de junio de 2012). Discurso da Presidenta da República, Dilma Rousseff, por ocasião de cerimônia de abertura protocolar da Conferência das Nacões Unidas sobre Desenvolvimento Sustentável (Rio+20). Recuperado de https://www.gov.br/mre/pt-br/centrais-de-conteudo/publicacoes/discursos-artigos-e-entrevistas/presidente-da-republica/ presidente-da-republica-federativa-do-brasil-discursos/discurso-da-presidenta-da-republica-dilma-rousseff-durante-cerimonia-de-abertura-protocolar-da-conferencia-das-nacoes-unidas-sobre-desenvolvimento-sustentavel-rio-20

Rousseff, D. (17 de junio de 2013). Discurso da Presidenta da República, Dilma Rousseff, por ocasião de formatura da turma 2011/2013 do Instituto Rio Branco. Recuperado de https:/ /www.gov.br/mre/pt-br/ centrais-de-conteudo/publicacoes/discursos-artigos-e-entrevistas/ presidente-da-republica/presidente-da-republica-federativa-do-brasil-discursos/discurso-da-presidenta-da-republica-dilma-rousseff-durante-cerimonia-de-formatura-da-turma-2011-2013-do-instituto-rio-branco Rousseff, D. (24 de septiembre de 2013). Discurso da Presidenta da República, Dilma Rousseff, por ocasião de mesa de abertura do Foro Politico de Alto Nivel sobre Desenvolvimento Sustentável. Recuperado de https://www.gov.br/mre/pt-br/centrais-de-conteudo/publicacoes/discursos-artigos-e-entrevistas/ presidente-da-republica/presidente-da-republica-federativa-do-brasil-discursos/discurso-da-presidenta-da-republica-dilma-rousseff-durante-mesa-de-abertura-do-foro-politico-de-alto-nivel-sobre-desenvolvimento-sustentavel-nova-iorque-estados-unidos-24-de-setembro-de-2013

Rousseff, D. (30 de abril de 2014). Discurso da Presidenta da República, Dilma Rousseff, por ocasião da cerimônia de formatura da turma 2012-2014 do Instituto Rio Branco e de imposição de insignias da Ordem de Rio Branco. Recuperado de https://www.gov.br/mre/pt-br/centrais-de-conteudo/ publicacoes/discursos-artigos-e-entrevistas/presidente-da-republica/ presidente-da-republica-federativa-do-brasil-discursos/discurso-da-presidenta-da-republica-dilma-rousseff-durante-cerimonia-de-formatura-da-turma-2012-2014-do-instituto-rio-branco-e-de-imposicao-de-insignias-da-ordem-de-rio-branco-brasilia-30-de-abril-de-2014 Rousseff, D. (24 de enero de 2014). Discurso proferido pela Presidenta da República, Dilma Rousseff, por ocasião de Sessão Plenária do Fórum Econômi- 
co Mundial 2014. Recuperado de https://www.gov.br/mre/pt-br/ centrais-de-conteudo/publicacoes/discursos-artigos-e-entrevistas/ presidente-da-republica/presidente-da-republica-federativa-do-brasil-discursos/discurso-proferido-pela-presidenta-da-republica-dilma-rousseff-durante-sessao-plenaria-do-forum-economico-mundial-2014 Rousseff, D. (28 de enero de 2014). Discurso da Presidenta da República, Dilma Rousseff, por ocasião da I sessão de trabalho da II Cúpula da Comunidade dos Estados Latino-Americanos (CELAC) - Havana. Recuperado de https://www.gov.br/mre/pt-br/centrais-de-conteudo/ publicacoes/discursos-artigos-e-entrevistas/presidente-da-republica/ presidente-da-republica-federativa-do-brasil-discursos/discurso-da-presidenta-da-republica-dilma-rousseff-durante-a-i-sessao-de-trabalho-da-ii-cupula-da-comunidade-dos-estados-latino-americanos-celac-havana-cuba-28-de-janeiro-de-2014

Rousseff, D. (19 de mayo de 2015a). Discurso da Presidenta da República, Dilma Rousseff, por ocasião do almoço em homenagem ao Primeiro-Ministro da República Popular da China, Li Keqiang e senhora Cheng Hong - Palácio do Planalto. Recuperado de https://www.gov.br/mre/pt-br/centrais-de-conteudo/ publicacoes/discursos-artigos-e-entrevistas/presidente-da-republica/ presidente-da-republica-federativa-do-brasil-discursos/discurso-da-presidenta-da-republica-dilma-rousseff-durante-almoco-em-homenagem-ao-primeiro-ministro-da-republica-popular-da-china-li-keqiang-e-senhora-cheng-hong-palacio-do-planalto-19-de-maio-de-2015

Rousseff, D. (27 de septiembre de 2015b). Discurso da Presidenta da República, Dilma Rousseff, durante Sessão Plenária da Conferência das Nações Unidas para a Agenda de Desenvolvimento Pós-2015. Recuperado de https://www.gov.br/mre/pt-br/centrais-de-conteudo/publicacoes/discursos-artigos-e-entrevistas/presidente-da-republica/ presidente-da-republica-federativa-do-brasil-discursos/discurso-da-presidenta-da-republica-dilma-rousseff-durante-sessao-plenaria-da-conferencia-das-nacoes-unidas-para-a-agenda-de-desenvolvimento-pos-2015-nova-york-27-de-setembro-de-2015

Schreirer, M. (2012). Qualitative content analysis in practice. Sage.

de Seixas Corrêa, L. F. (2012). O Brasil nas Nações Unidas: 1946-2011. Fundação Alexandre de Gusmão (FUNAG). 
Serra, J. (2016). Apresentação. En S. E. Moreira Lima, Brasil e China. 40 anos de relações diplomáticas. Análises e documentos (pp. 9-13). Fundação Alexandre de Gusmão (FUNAG).

da Silva, L.I. (20 de octubre de 2004a). Discurso do Senhor Presidente da República, Luiz. Inácio Lula da Silva, durante reunião da Comissão Mundial sobre a Dimensão Social da Globalização. Recuperado de http://www4.planalto. gov.br/consea/comunicacao/discursos/2004/discurso-do-presidente-da-republica-luiz-inacio-lula-da-silva-durante-reuniao-da-comissao-mundial-sobre-a-dimensao-social-da-globalizacao.pdf

da Silva, L.I. (20 de septiembre de 2004b). Luiz Inácio Lula da Silva: Discurso do Senhor Presidente da República, Luiz Inácio Lula da Silva, na Reunião de Lideres Mundiais para a "Ação contra a Fome e a Pobrez̧a". Recuperado de https://politica.estadao.com.br/noticias/geral,discurso-de-lula-na-reuniao-acao-contra-a-fome-e-a-pobreza,20040920p37800

da Silva, L.I (20 de septiembre de 2004c). Palavras do Senhor Presidente da República, Luiz Inácio Lula da Silva, no encerramento da Reunião de Líderes Mundiais para a "Ação contra a Fome e a Pobreza. En S. E. Moreira Lima, Brasile China. 40 anos de relações diplomáticas. Análises e documentos (pp. 731-733). Fundação Alexandre de Gusmão (FUNAG). da Silva, L. I. (14 de diciembre de 2005a). Discurso do Senhor Presidente da República, Luiz Inácio Lula da Silva, no Debate de Alto Nível sobre Financiamento ao Desenvolvimento. En S. E. Moreira Lima, Brasile China. 40 anos de relações diplomáticas. Análises e documentos (pp. 739-741). Fundação Alexandre de Gusmão (FUNAG).

da Silva, L. I. (2005b). Discurso do Senhor Presidente da República, Luiz Inácio Lula da Silva, na Reunião de Cúpula do Conselho de Segurança das Nações Unidas. En S. E. Moreira Lima, Brasil e China. 40 anos de relações diplomáticas. Análises e documentos (pp. 743-746). Fundação Alexandre de Gusmão (FUNAG).

da Silva, L. I. (15 de septiembre de 2005c). Discurso do Senhor Presidente da República, Luiz Inácio Lula da Silva, por ocasião da Reunião de Alto Nível da Assembleia Geral das Nações Unidas sobre a Implementação das Metas do MilênioEn S. E. En L. F. de Seixas Corrêa (Org.), O Brasil nas Nações Unidas: 1946-2011 (pp. 835-839). Fundação Alexandre de Gusmão (FUNAG).

da Silva, L. I. (21 de julio de 2006). Discurso do Presidente da República, Luiz. Inácio Lula da Silva, por ocasião do Diálogo Aberto dos Presidentes na Cúpula 
do Mercosul. Recuperado de https://www.gov.br/mre/pt-br/centrais-de-conteudo/publicacoes/discursos-artigos-e-entrevistas/presidente-da-republica/presidente-da-republica-federativa-do-brasil-discursos/ discurso-do-presidente-da-republica-luiz-inacio-lula-da-silva-por-ocasiao-do-dialogo-aberto-dos-presidentes-na-cupula-do-mercosul-cordoba-argentina-21-07-2006

da Silva, L. I. (1 de diciembre de 2008a). Discurso do Presidente da República, Luiz. Inácio Lula da Silva, por ocasião do Fórum Brasileiro de Mudanças Climáticas. Recuperado de https://www.gov.br/mre/pt-br/centrais-de-conteudo/publicacoes/discursos-artigos-e-entrevistas/presidente-da-republica/presidente-da-republica-federativa-do-brasil-discursos/ discurso-do-presidente-da-republica-luiz-inacio-lula-da-silva-por-ocasiao-do-forum-brasileiro-de-mudancas-climaticas-brasilia-1-de-dezembro-de-2008

da Silva, L. I. (17 de diciembre de 2008b). Discurso do Presidente da República, Luiz Inácio Lula da Silva, por ocasião de encerramento da Cúpula da América Latina e do Caribe sobre Integração e Desenvolvimento (CALC). Recuperado de https://www.gov.br/mre/pt-br/centrais-de-conteudo/publicacoes/discursos-artigos-e-entrevistas/presidente-da-republica/ presidente-da-republica-federativa-do-brasil-discursos/discurso-do-presidente-da-republica-luiz-inacio-lula-da-silva-por-ocasiao-de-encerramento-da-cupula-da-america-latina-e-do-caribe-sobre-integracao-e-desenvolvimento-calc-costa-do-sauipe-17-de-dezembro-de-2008 da Silva, L.I. (septiembre de 2008c). Discurso do Senhor Presidente da República, Luiz Inácio Lula da Silva, por ocasião da Reunião de Alto Nível da Assembleia Geral das Nações Unidas sobre a Implementação das Metas do MilênioEn S. E. En L. F. de Seixas Corrêa (Org.), O Brasil nas Nações Unidas. 1946-2011 (pp. 929-923). Fundação Alexandre de Gusmão (FUNAG).

da Silva, L. I. (7 de mayo de 2009). Discurso do Presidente da República, Luiz Inácio Lula da Silva, por ocasião de comemoração ao Dia do Diplomata. Recuperado de https://www.gov.br/mre/pt-br/centrais-de-conteudo/ publicacoes/discursos-artigos-e-entrevistas/presidente-da-republica/ presidente-da-republica-federativa-do-brasil-discursos/discurso-do-presidente-da-republica-luiz-inacio-lula-da-silva-por-ocasiao-de-comemoracao-ao-dia-do-diplomata-palacio-itamaraty-07-de-maio-de-2009 
da Silva, L. I. (20 de abril de 2010). Discurso do Presidente da República, Luiz. Inácio Lula da Silva, por ocasião de comemoração ao Dia do Diplomata. Recuperado de https://www.gov.br/mre/pt-br/centrais-de-conteudo/ publicacoes/discursos-artigos-e-entrevistas/presidente-da-republica/ presidente-da-republica-federativa-do-brasil-discursos/discurso-durante-cerimonia-em-comemoracao-ao-dia-do-diplomata-palacio-itamaraty-brasilia-20-04-2010

da Silva, L. I. (2012). LVIII Sessão Ordinária da Assembleia Geral das Nações Unidas 2003. En L. F. de Seixas Corrêa (Org.), O Brasil nas Nações Unidas: 1946-2011 (pp. 835-839). Fundação Alexandre de Gusmão (FUNAG).

da Silva, L. (Marzo de 2009). Entrevista exclusiva concedida pelo Presidente da República. (R. BBC, Entrevistador)

da Silva, L. I., \& Jintao, H. (2016). Plano de Ação Conjunta Brasil-China 2010-2014. En S. E. Moreira Lima, Brasil e China. 40 anos de relações diplomáticas. Análises e documentos (pp. 361-405). Fundação Alexandre de Gusmão (FUNAG).

Nunes, A. (8 de diciembre de 2017). Discurso do Ministro Aloysio Nunes Ferreira no II Seminário sobre Diplomacia e Inovação Cientifica e Tecnológica-Brasilia, 8 de dezembro de 2017. Recuperado de https:/ / www.gov.br/mre/pt-br/ centrais-de-conteudo/publicacoes/discursos-artigos-e-entrevistas/ ministro-das-relacoes-exteriores/discursos-mre/discurso-do-ministro-aloysio-nunes-ferreira-no-ii-seminario-sobre-diplomacia-e-inovacao-cientifica-e-tecnologica-brasilia-8-de-dezembro-de-2017

Solano Gallego, E. (2018). Brasil bajo Bolsonaro: desafíos inmediatos. Recuperado de http://www.realinstitutoelcano.org/wps/portal/rielcano_es/ contenido?WCM_GLOBAL_CONTEXT=/elcano/elcano_es / zonas_es/ari118-2018-solanogallego-brasil-bolsonaro-desafios-inmediatos

Temer, M. (Septiembre de 2016). Entrevista exclusiva concedida pelo Presidente da República, Michel Temer. (RON York, Entrevistador)

Temer, M. (16 de diciembre de 2016). Discurso do Presidente da República, Michel Temer, durante Cerimônia de entrega da Ordem de Rio Branco e da Ordem do Mérito da Defesa a cidadãos colombianos e ao Prefeito de Chapecó - Palácio do Planalto. Recuperado de http://antigo.itamaraty.gov.br/pt-BR/discursos-artigos-e-entrevistas-categoria/presidente-da-republica-federativa-do-brasil-discursos/15499-discurso-do-presidente-da-republica- 
michel-temer-durante-cerimonia-de-entrega-da-ordem-de-rio-branco-e-da-ordem-do-merito-da-defesa-a-cidadaos-colombianos-e-ao-prefeito-de-chapeco-palacio-do-planalto-16-de-dezembro-de-2016

Temer, M. (19 de septiembre de 2017). Discurso do Presidente da República, Michel Temer, na Abertura do Debate Geral da $72^{\circ}$ Sessão da Assembleia Geral da ONU. Recuperado de https://www.gov.br/mre/pt-br/centrais-deconteudo/publicacoes/discursos-artigos-e-entrevistas/presidenteda-republica/presidente-da-republica-federativa-do-brasil-discursos/ discurso-do-presidente-da-republica-michel-temer-na-abertura-dodebate-geral-da-72-sessao-da-assembleia-geral-da-onu-nova-york19-de-setembro-de-2017

Temer, M. (25 de septiembre de 2018a). Discurso do Presidente Michel Temer na abertura do Debate Geral da $73^{a}$ Sessão da Assembleia Geral das Nações Unidas. Recuperado de https://www.gov.br/mre/pt-br/centrais-de-conteudo/publicacoes/discursos-artigos-e-entrevistas/presidente-da-republica/presidente-da-republica-federativa-do-brasil-discursos/ discurso-do-presidente-michel-temer-na-abertura-do-debate-geral-da-73-sessao-da-assembleia-geral-das-nacoes-unidas-2

Temer, M. (14 de abril de 2018b). Discurso do Presidente da República, Michel Temer, em Sessão Plenária da VIII Cúpula das Américas. Recuperado de https://www.gov.br/mre/pt-br/centrais-de-conteudo/publicacoes/ discursos-artigos-e-entrevistas/presidente-da-republica/presidente-da-republica-federativa-do-brasil-discursos/discurso-do-presidente-da-republica-michel-temer-em-sessao-plenaria-da-viii-cupula-das-americas-lima-peru-14-de-abril-de-2018

Temer, M. (30 de noviembre de 2018c). Discurso do presidente Michel Temer na I Sessão Plenária da Reunião de Líderes do G20 - Buenos Aires. Recuperado de https://www.gov.br/mre/pt-br/centrais-de-conteudo/ publicacoes/discursos-artigos-e-entrevistas/presidente-da-republica/ presidente-da-republica-federativa-do-brasil-discursos/discurso-do-presidente-michel-temer-na-i-sessao-plenaria-da-reuniao-de-lideres-do-g20-buenos-aires-30-de-novembro-de-2018

Temer, M. (30 de noviembre de 2018d). Discurso do presidente Michel Temer na II Sessão Plenária da Reunião de Líderes do G20 - Construindo Consenso - Buenos Aires. Recuperado de https://www.gov.br/mre/pt-br/ centrais-de-conteudo/publicacoes/discursos-artigos-e-entrevistas/ presidente-da-republica/presidente-da-republica-federativa-do- 
brasil-discursos/discurso-do-presidente-michel-temer-na-ii-sessao-plenaria-da-reuniao-de-lideres-do-g20-construindo-consenso-buenos-aires-30-de-novembro-de-2018

Thies, C. (2014). Role theory and foreign policy analysis in Latin America. Foreign Policy Analysis, 13(3), 662-681. Recuperado de https://doi. org $/ 10.1111 /$ fpa.12072

Walker, S., \& Sheldon, S. R. (1987). Role sets and foreign policy analysis in Southeast Asia. En S. G. Walker, Role theory and foreign policy analysis (pp. 141-159). Duke University Press.

Wish, N. (1987). National Attributes as Sources of National Role Conceptions: A Capability-Motivation Model. En S. G. Walker, In Role Theory and Foreign Policy Analysis (pp. 94-108). Duke University Press.

World Bank. (2020). Brazilian GDP evolution. Recuperado de https://data. worldbank.org/indicator/NY.GDP.PCAP.KD.ZG?locations=BR 